\title{
Proposal of a follow-up imaging strategy following Pipeline flow diversion treatment of intracranial aneurysms
}

\author{
${ }^{*}$ Raghav Gupta, BS, ${ }^{1}$ Christopher S. Ogilvy, MD,1 Justin M. Moore, MD, PhD, ${ }^{1}$ \\ Christoph J. Griessenauer, MD, ${ }^{1,2}$ Alejandro Enriquez-Marulanda, MD, ${ }^{1}$ Madeline Leadon, BA, ${ }^{1}$ \\ Nimer Adeeb, MD, ${ }^{1}$ Luis Ascanio, MD, ${ }^{1}$ Georgios A. Maragkos, MD, ${ }^{1}$ Abhi Jain, DPT, MEd, ${ }^{2}$ \\ Philip G. R. Schmalz, MD, ${ }^{1}$ Abdulrahman Y. Alturki, MBBS, MSc, FRCSC, ${ }^{1}$ \\ Kimberly Kicielinski, MD, ${ }^{1}$ Clemens M. Schirmer, MD, PhD, ${ }^{2}$ and Ajith J. Thomas, MD'
}

\begin{abstract}
${ }^{1}$ Neurosurgical Service, Beth Israel Deaconess Medical Center, Harvard Medical School, Boston, Massachusetts; and 2Department of Neurosurgery, Geisinger Medical Center, Danville, Pennsylvania
\end{abstract}

\begin{abstract}
OBJECTIVE There is currently no standardized follow-up imaging strategy for intracranial aneurysms treated with the Pipeline embolization device (PED). Here, the authors use follow-up imaging data for aneurysms treated with the PED to propose a standardizable follow-up imaging strategy.
\end{abstract}

METHODS A retrospective review of all patients who underwent treatment for ruptured or unruptured intracranial aneurysms with the PED between March 2013 and March 2017 at 2 major academic institutions in the US was performed.

RESULTS A total of 218 patients underwent treatment for 259 aneurysms with the PED and had undergone at least 1 follow-up imaging session to assess aneurysm occlusion status. There were $235(90.7 \%)$ anterior and 24 posterior $(9.3 \%)$ circulation aneurysms. On Kaplan-Meier analysis, the cumulative incidences of aneurysm occlusion at 6, 12, 18, and 24 months were $38.2 \%, 77.8 \%, 84.2 \%$, and $85.1 \%$, respectively. No differences in the cumulative incidence of aneurysm occlusion according to aneurysm location $(p=0.39)$ or aneurysm size $(p=0.81)$ were observed. A trend toward a decreased cumulative incidence of aneurysm occlusion in patients 70 years or older was observed $(p=0.088)$. No instances of aneurysm rupture after PED treatment or aneurysm recurrence after occlusion were noted. Sixteen (6.2\%) aneurysms were re-treated with the PED; 11 of these had imaging follow-up data available, demonstrating occlusion in 3 $(27.3 \%)$.

CONCLUSIONS The authors propose a follow-up imaging strategy that incorporates 12-month digital subtraction angiography and 24-month MRA for patients younger than 70 years and single-session digital subtraction angiography at 12 months in patients 70 years or older. For recurrent or persistent aneurysms, re-treatment with the PED or use of an alternative treatment modality may be considered.

https://thejns.org/doi/abs/10.3171/2018.2.JNS172673

KEYWORDS intracranial aneurysm; occlusion rate; cerebrovascular; follow-up imaging; flow diversion; rupture; vascular disorders

$\mathrm{I}$ NTRACRANIAL aneurysms are being increasingly detected due to the more frequent use of noninvasive cerebrovascular imaging modalities. ${ }^{23}$ Unruptured aneurysms have a prevalence of $3.2 \%$ in the general population. ${ }^{6}$ Flow diversion with the Pipeline embolization device (PED; Medtronic, Inc.) has become a mainstay in the endovascular management of these lesions in the United States. ${ }^{1-3,7-9,11-13,17-22}$ The PED serves as a scaffold for neointimal growth along the length of the aneurysm neck and promotes thrombosis of the lesion via diversion of blood flow away from the aneurysm sac. Previous data demonstrated 6-month and 12-month occlusion rates of 90\% and

ABBREVIATIONS DSA = digital subtraction angiography; ICA = internal carotid artery; $m R S=$ modified Rankin Scale; PED = Pipeline embolization device. SUBMITTED October 22, 2017. ACCEPTED February 8, 2018.

INCLUDE WHEN CITING Published online July 13, 2018; DOI: 10.3171/2018.2.JNS172673.

${ }^{*}$ A.E.M. and M.L. contributed equally to this work. 
95\% following PED placement, respectively.-9,18,19,21-23 After treatment, patients undergo follow-up via a combination of MRA, CTA, and/or digital subtraction angiography (DSA) to assess aneurysm occlusion status over time.

A recent survey of academic neurovascular centers in the US, however, found that a standardized follow-up imaging strategy has not yet been established and that there is significant heterogeneity with regard to the imaging strategies that were employed to monitor patients who have undergone flow diversion treatment. ${ }^{14} \mathrm{Of}$ note, the costs of these strategies can vary from $\$ 2788$ to $\$ 46,670$ depending on the frequency at which angiograms are obtained..$^{14}$ In the present study, we aimed to identify the point at which aneurysms become occluded over time after PED placement. Using these data, we propose a standardizable follow-up imaging strategy.

\section{Methods \\ Data Collection}

Approval was obtained from the IRB at both institutions prior to beginning this study. A retrospective review of all patients who underwent treatment of either ruptured or unruptured intracranial aneurysms with the PED between March 2013 and March 2017 at 2 major academic institutions in the US was performed. Aneurysms that did not have follow-up imaging data available were excluded from the analysis. Patient demographics (e.g., age, sex, smoking status), aneurysm characteristics (e.g., location, previous treatment, morphology, maximum diameter), clinical presentation (e.g., pretreatment modified Rankin Scale [mRS] score, rupture status), and treatment parameters (e.g., number of PEDs used, adjunctive coil embolization) were recorded. For aneurysms located within the internal carotid artery (ICA), the Bouthillier classification system was used. ${ }^{5}$ Aneurysm size was classified into 4 different categories: < $7.0 \mathrm{~mm}, 7.0-9.9 \mathrm{~mm}, 10.0-19.9 \mathrm{~mm}$, and $\geq 20.0 \mathrm{~mm}$. Intraoperative, postoperative, and symptomatic hemorrhagic and thromboembolic complications were noted. Clinical follow-up duration and the mRS score at last follow-up were recorded.

\section{Imaging Follow-Up}

Time to aneurysm occlusion and the imaging modality (MRA, CTA, or DSA) used to confirm occlusion were noted. Follow-up imaging protocols at both institutions dictated that angiography be performed for the initial assessment of aneurysm occlusion status; MRA or CTA were performed in noncompliant patients or in patients in whom angiography was contraindicated. At both institutions, DSA was performed 6 months post-PED placement for initial assessment of aneurysm occlusion status. If the aneurysm was occluded at this point, one institution performed MRA 2 years post-PED placement. If the aneurysm was not occluded on the initial angiogram, another DSA study was obtained 1 year after PED placement. The other institution performed MRA 1 and 2 years after PED placement regardless of aneurysm occlusion status. Aneurysms were classified as completely occluded (100\%), nearly completely occluded $(90 \%-100 \%)$, or incompletely occluded $(<90 \%)$ at each radiographic follow-up. Occlu- sion status was assessed by 3 readers (C.Y.G., A.E.M., and A.Y.A.), who were blinded to outcomes (the 3 readers did not read the same studies). The length of radiographic follow-up, as well as aneurysm occlusion status at last follow-up, were assessed. Instances of aneurysm rupture post-PED treatment were recorded. Aneurysms that were re-treated with the PED were noted.

\section{Statistical Analysis}

Mean and median values are reported for normally and nonnormally distributed variables, respectively. The standard deviation and interquartile range are reported alongside mean and median values, respectively. The Kaplan-Meier estimator statistic was used to assess the relationship between length of imaging follow-up and cumulative incidence of aneurysm occlusion. Comparative Kaplan-Meier curves were developed to assess the effect of patient age, aneurysm location (anterior vs posterior intracranial circulation), and maximum aneurysm diameter on the cumulative incidence of aneurysm occlusion over time. The log-rank test was used for assessing statistically significant differences in Kaplan-Meier curve distributions. A p value $<0.05$ was considered significant. All statistical analyses were performed using the STATA software (StataCorp LLC).

\section{Results \\ Patient Demographics}

A total of 298 aneurysms underwent flow diversion treatment with the PED between March 2013 and March 2017. Of these, 259 aneurysms (in 218 patients) had at least one follow-up imaging study to assess aneurysm occlusion status and were included in the analysis. The mean age of these patients was $57.8 \pm 12.6$ years. Most patients (179; $82.1 \%$ ) were younger than 70 years at the time of treatment and had an mRS score of $0-2(210 ; 96.4 \%)$ at the time of presentation. Forty-six (21.1\%) patients identified as current or previous smokers. At the last follow-up, 206 (97.2\%) patients had an mRS score of 0-2. Two patients died during the follow-up period (Table 1).

\section{Aneurysm Characteristics}

Most aneurysms $(225 ; 86.9 \%)$ were of a saccular morphology and were located within the ophthalmic segment of the ICA (148; 57.1\%). There were 235 (90.7\%) anterior and 24 posterior $(9.3 \%)$ circulation aneurysms included in the analysis. The median maximum aneurysm diameter was $7.0 \mathrm{~mm}$ (IQR 4.6-12.0 mm), and 89 (34.4\%) aneurysms had a diameter of $\geq 10 \mathrm{~mm}$. A majority $(249 ; 96.1 \%)$ of aneurysms treated with the PED were unruptured aneurysms. Thirty-seven (14.3\%) aneurysms had been previously treated via endovascular coil embolization. At the last radiographic follow-up, at a median of 8.7 (IQR 6.217.2) months after PED treatment, 200 (77.2\%) aneurysms were occluded. DSA was used to confirm occlusion in 175 $(87.5 \%)$ cases. Either MRA $(10 ; 5.0 \%)$ or CTA $(15 ; 7.5 \%)$ was used to confirm occlusion in the remaining cases. The median follow-up durations for aneurysms that were incompletely occluded and nearly completely occluded were 14.7 months (IQR 6.9-24.0 months) and 7.7 months (IQR 
TABLE 1. Patient demographics, aneurysm characteristics, and treatment parameters

\begin{tabular}{|c|c|}
\hline Parameter & Value \\
\hline \multicolumn{2}{|l|}{ Patient demographics } \\
\hline No. of patients & 218 \\
\hline \multicolumn{2}{|l|}{ Sex } \\
\hline Male & $36(16.5 \%)$ \\
\hline Female & $182(83.5 \%)$ \\
\hline Mean age $\pm S D$ at time of treatment, yrs & $57.8 \pm 12.6$ \\
\hline \multicolumn{2}{|l|}{ Age, yrs } \\
\hline$<70$ & $179(82.1 \%)$ \\
\hline$\geq 70$ & $39(17.9 \%)$ \\
\hline Smoking history & $46(21.1 \%)$ \\
\hline \multicolumn{2}{|l|}{ Pretreatment mRS score } \\
\hline 0 & $132(60.6 \%)$ \\
\hline 1 or 2 & $78(35.8 \%)$ \\
\hline $3-5$ & $8(3.7 \%)$ \\
\hline \multicolumn{2}{|l|}{ mRS score at last follow-up* } \\
\hline 0 & $143(67.5 \%)$ \\
\hline 1 or 2 & $63(29.7 \%)$ \\
\hline $3-5$ & $4(1.8 \%)$ \\
\hline 6 & $2(0.9 \%)$ \\
\hline \multicolumn{2}{|l|}{ Aneurysm characteristics } \\
\hline No. of aneurysms & 259 \\
\hline \multicolumn{2}{|l|}{ Aneurysm location } \\
\hline Anterior circulation & $235(90.7 \%)$ \\
\hline \multicolumn{2}{|l|}{ ICA† } \\
\hline Cervical $\left(C_{1}\right)$ & $4(1.5 \%)$ \\
\hline Petrous $\left(\mathrm{C}_{2}\right)$ & $1(0.4 \%)$ \\
\hline Lacerum $\left(\mathrm{C}_{3}\right)$ & 0 \\
\hline Cavernous $\left(\mathrm{C}_{4}\right)$ & $37(14.3 \%)$ \\
\hline Clinoid $\left(\mathrm{C}_{5}\right)$ & $14(5.4 \%)$ \\
\hline Ophthalmic/supraclinoid $\left(\mathrm{C}_{6}\right)$ & $148(57.1 \%)$ \\
\hline Communicating/terminal $\left(\mathrm{C}_{7}\right)$ & $19(7.3 \%)$ \\
\hline Other (e.g., $\left.C_{4}-C_{5}\right)$ & $3(1.2 \%)$ \\
\hline MCA & $6(2.3 \%)$ \\
\hline ACA & $3(1.2 \%)$ \\
\hline Posterior circulation & $24(9.3 \%)$ \\
\hline PCA & $4(1.5 \%)$ \\
\hline Basilar trunk or tip & $6(2.3 \%)$ \\
\hline SCA & $1(0.4 \%)$ \\
\hline AICA or PICA & $4(1.5 \%)$ \\
\hline VA & $9(3.5 \%)$ \\
\hline \multicolumn{2}{|l|}{ Aneurysm morphology } \\
\hline Saccular & $225(86.9 \%)$ \\
\hline Fusiform/dissecting/blister & $34(13.1 \%)$ \\
\hline Median maximum diameter, mm (IQR) & $7.0(4.6-12.0)$ \\
\hline$<7.0$ & $120(46.3 \%)$ \\
\hline $7.0-9.9$ & $50(19.3 \%)$ \\
\hline $10.0-19.9$ & $69(26.6 \%)$ \\
\hline$\geq 20.0$ & $20(7.7 \%)$ \\
\hline
\end{tabular}

CONTINUED IN NEXT COLUMN »
» CONTINUED FROM PREVIOUS COLUMN

TABLE 1. Patient demographics, aneurysm characteristics, and treatment parameters

\begin{tabular}{|c|c|}
\hline Parameter & Value \\
\hline \multicolumn{2}{|l|}{ Aneurysm characteristics (continued) } \\
\hline \multicolumn{2}{|l|}{ Presentation } \\
\hline Ruptured & $10(3.9 \%)$ \\
\hline Unruptured & $249(96.1 \%)$ \\
\hline \multicolumn{2}{|l|}{ Previously treated } \\
\hline Coil embolization & $37(14.3 \%)$ \\
\hline Microsurgical clipping & $5(1.9 \%)$ \\
\hline Coil embolization + microsurgical clipping & $1(0.4 \%)$ \\
\hline Adjunctive coil embolization & $4(1.5 \%)$ \\
\hline \multicolumn{2}{|l|}{$\begin{array}{l}\text { Aneurysm occlusion status at last radiographic } \\
\text { follow-up }\end{array}$} \\
\hline Occluded $(100 \%)$ & $200(77.2 \%)$ \\
\hline Near-completely occluded (90-100\%) & $22(8.5 \%)$ \\
\hline Incompletely occluded (<90\%) & $37(14.3 \%)$ \\
\hline \multicolumn{2}{|l|}{ Modality used to confirm occlusion } \\
\hline DSA & $175(87.5 \%)$ \\
\hline MRA & $10(5.0 \%)$ \\
\hline CTA & $15(7.5 \%)$ \\
\hline Median radiographic follow-up, mos (IQR) & $8.7(6.2-17.2)$ \\
\hline Near-completely occluded (90-100\%) & $7.7(6.0-13.3)$ \\
\hline Incompletely occluded (<90\%) & $14.7(6.9-24.0)$ \\
\hline Median clinical follow-up, mos (IQR) & $6.9(1.2-16.8)$ \\
\hline Re-treatment w/ PED & $16(6.2 \%)$ \\
\hline Follow-up imaging performed & $11(68.8 \%)$ \\
\hline Median follow-up length, mos (IQR) & $11.0(6.0-23.0)$ \\
\hline Occluded at last follow-up & $3(27.3 \%)$ \\
\hline \multicolumn{2}{|l|}{ Procedural parameters } \\
\hline No. of procedures & 231 \\
\hline \multicolumn{2}{|l|}{ No. of PEDs placed per procedure } \\
\hline 1 & $213(92.2 \%)$ \\
\hline 2 & $16(6.9 \%)$ \\
\hline 3 & $1(0.4 \%)$ \\
\hline 4 & 0 \\
\hline 5 & $1(0.4 \%)$ \\
\hline \multicolumn{2}{|l|}{ Procedural complications } \\
\hline Thromboembolic & $12(5.2 \%)$ \\
\hline Intraoperative & $6(2.6 \%)$ \\
\hline Postoperative & $6(2.6 \%)$ \\
\hline Symptomatic & $8(3.5 \%)$ \\
\hline Hemorrhagic & $4(1.7 \%)$ \\
\hline Intraoperative & $2(0.9 \%)$ \\
\hline Postoperative & $2(0.9 \%)$ \\
\hline Symptomatic & $3(1.3 \%)$ \\
\hline
\end{tabular}

$\mathrm{ACA}=$ anterior cerebral artery; $\mathrm{AICA}=$ anterior inferior cerebellar artery; $\mathrm{MCA}$ $=$ middle cerebral artery; $\mathrm{PCA}=$ posterior cerebral artery; $\mathrm{PICA}=$ posterior inferior cerebellar artery; $\mathrm{VA}=$ vertebral artery.

* Data missing for 6 patients

† Bouthillier classification system. 
TABLE 2. Comparison of occluded and incompletely occluded aneurysms that were re-treated with PEDs

\begin{tabular}{lcc}
\hline \multicolumn{1}{c}{ Factor } & $\begin{array}{c}\text { Occluded } \\
(\mathrm{n}=3)\end{array}$ & $\begin{array}{c}\text { Not Occluded } \\
(\mathrm{n}=8)\end{array}$ \\
\hline Mean maximum diameter, mm & 6.4 & 7.8 \\
\hline Shape & & \\
\hline Saccular & $3(100 \%)$ & $7(87.5 \%)$ \\
\hline Fusiform & 0 & $1(12.5 \%)$ \\
\hline Location & & \\
\hline Anterior & $3(100 \%)$ & $7(87.5 \%)$ \\
\hline Posterior & & $1(12.5 \%)$ \\
\hline Mean patient age, yrs & 56.5 & 56.4 \\
\hline
\end{tabular}

6.0-13.3 months), respectively, giving a combined imaging follow-up of 12.1 months (IQR 7.0-20.9 months) after treatment. Fifty-nine (22.8\%) aneurysms underwent imaging follow-up $\geq 18$ months post-PED placement. No instances of aneurysm rupture or rerupture after PED treatment were observed.

\section{Procedural Parameters}

A total of 231 procedures were performed; in most cases (92.2\%), a single PED device was placed. Adjunctive coil embolization was performed in $4(1.5 \%)$ aneurysms. There were $12(5.2 \%)$ and $4(1.7 \%)$ thromboembolic and hemorrhagic complications, respectively. Eleven (4.8\%) of these complications were symptomatic. Sixteen (6.2\%) aneurysms were re-treated. Of note, each of these lesions was incompletely occluded at the initial 6-month angiographic follow-up. Follow-up imaging after re-treatment was performed in 11 cases at a median of 11.0 months post-PED placement. Three (27.3\%) of these aneurysms were occluded (Table 2).

\section{Kaplan-Meier Occlusion Analysis}

On Kaplan-Meier analysis, the cumulative incidences of aneurysm occlusion at $6,12,18$, and 24 months were
$38.2 \%, 77.8 \%, 84.2 \%$, and $85.1 \%$, respectively (Table 3 ). At 24 months, the cumulative incidences of occlusion were $85.0 \%$ for anterior circulation aneurysms and $84.2 \%$ for posterior circulation aneurysms. These differences were not statistically significant $(\mathrm{p}=0.39)$. When aneurysms were stratified by maximal diameter, the cumulative 24-month incidences of aneurysm occlusion were $86.6 \%$, $74.9 \%, 86.5 \%$, and $87.2 \%$ for $<7.0-\mathrm{mm}, 7.0-$ to $9.9-\mathrm{mm}$, 10.0 - to $19.9-\mathrm{mm}$, and $\geq 20.0-\mathrm{mm}$ lesions, respectively. Log-rank test analysis confirmed that these differences were not significant $(p=0.81)$. When stratified by patient age, a trend toward a lower cumulative incidence of aneurysm occlusion in patients $\geq 70$ years compared with patients $<70$ years was observed $(\mathrm{p}=0.088)$.

\section{Discussion \\ Background}

There is currently no standardized follow-up imaging strategy for intracranial aneurysms treated with the PED. ${ }^{14}$ Several studies have previously reported 6-month and 12-month occlusion rates of around $90 \%$ and $95 \%$, respectively. ${ }^{7,817-19,21-23}$ However, data regarding aneurysm recanalization or recurrence over time for aneurysms treated with this device are limited. A prior study on 11 aneurysms treated with the PED, which were all occluded after the 6-month angiographic follow-up, did not find any instances of aneurysm recurrence over a 2.5-year followup period. ${ }^{7}$ Aneurysm recurrence is particularly concerning for neurointerventionalists, as prior studies have found that the degree of initial aneurysm occlusion is an important predictor for subsequent rerupture, which is associated with a high rate of morbidity and mortality. ${ }^{15}$

Gupta et al. previously reported that a majority (73.1\%) of academic neurovascular centers in the US perform angiography at 6 months and up to 6 follow-up imaging studies within a 5-year period to assess for aneurysm recurrence following PED placement. As imaging studies are costly and have inherent risks of their own, the number of imaging studies and the time points at which they should be performed after PED placement must be clearly delin-

TABLE 3. Kaplan-Meier estimator statistic values

\begin{tabular}{lcccc}
\hline \multirow{2}{*}{ Parameter } & \multicolumn{3}{c}{ Cumulative Incidence of Aneurysm Occlusion (95\% Cl) } \\
\cline { 2 - 4 } & 6 Mos & 12 Mos & 18 Mos & 24 Mos \\
\hline Overall & $38.2 \%(32.5-44.5 \%)$ & $77.8 \%(72.1-82.9 \%)$ & $84.2 \%(78.6-88.9 \%)$ & $85.1 \%(79.6-89.9 \%)$ \\
\hline Aneurysm circulation & & & & \\
\hline Anterior & $38.2 \%(32.3-44.8 \%)$ & $79.3 \%(73.5-84.5 \%)$ & $84.0 \%(78.3-88.8 \%)$ & $85.0 \%(79.3-89.8 \%)$ \\
\hline Posterior & $37.8 \%(21.7-60.1 \%)$ & $62.1 \%(42.5-81.7 \%)$ & $84.2 \%(62.3-97.0 \%)$ & $84.2 \%(62.3-97.0 \%)$ \\
\hline Maximum aneurysm diameter, mm & & & & \\
\hline$<7.0$ & $38.1 \%(30.1-47.6 \%)$ & $81.3 \%(73.4-88.0 \%)$ & $84.9 \%(77.2-91.1 \%)$ & $86.6 \%(78.8-92.6 \%)$ \\
\hline $7.0-9.9$ & $38.5 \%(26.6-53.6 \%)$ & $74.9 \%(61.5-86.6 \%)$ & $74.9 \%(61.5-86.6 \%)$ & $74.9 \%(61.5-86.6 \%)$ \\
\hline $10.0-19.9$ & $37.1 \%(26.8-49.7 \%)$ & $75.4 \%(64.1-85.3 \%)$ & $86.5 \%(75.7-94.1 \%)$ & $86.5 \%(75.7-94.1 \%)$ \\
\hline$\geq 20.0$ & $41.6 \%(23.3-66.4 \%)$ & $65.9 \%(44.1-86.3 \%)$ & $87.2 \%(60.5-99.0 \%)$ & $87.2 \%(60.5-99.0 \%)$ \\
\hline Age, yrs & & & & \\
\hline$<70$ & $39.1 \%(32.8-46.1 \%)$ & $79.9 \%(73.8-85.3 \%)$ & $87.8 \%(82.0-92.4 \%)$ & $88.9 \%(82.0-92.4 \%)$ \\
\hline$\geq 70$ & $34.1 \%(22.5-49.6 \%)$ & $66.8 \%(52.8-80.2 \%)$ & $66.8 \%(52.8-80.2 \%)$ & $66.8 \%(52.8-80.2 \%)$ \\
\hline
\end{tabular}




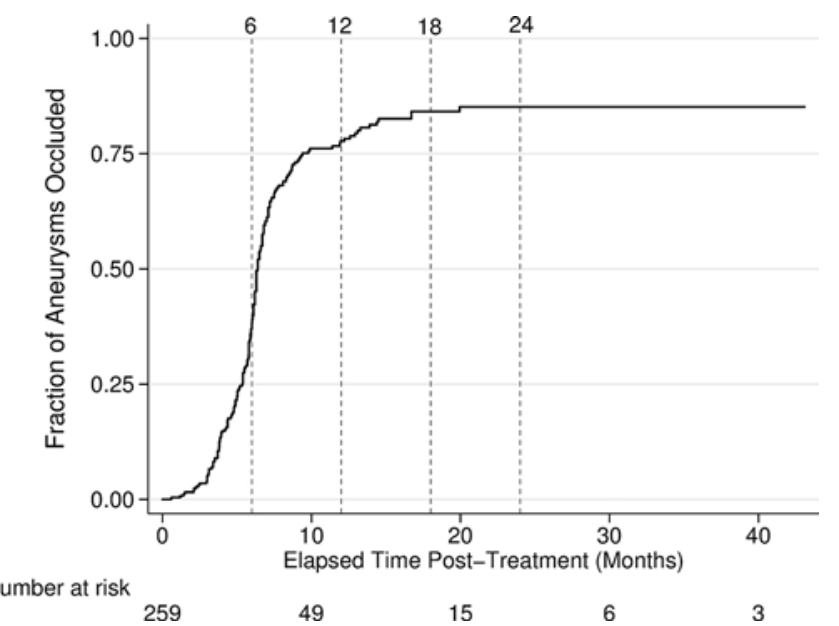

FIG. 1. Composite Kaplan-Meier estimator statistic curve depicting the cumulative incidence of aneurysm occlusion as a function of length of imaging follow-up.

eated. Cerebral angiography, for example, is invasive, can cost up to $\$ 13,820$ per study, ${ }^{14}$ and can lead to neurological complications in $1.3 \%$ of cases. ${ }^{24}$ Nearly one-third of these neurological complications may lead to permanent deficits. ${ }^{24}$

\section{Cumulative Incidence of Aneurysm Occlusion}

In the present study, an overall aneurysm occlusion rate of $77.2 \%$ was observed. On Kaplan-Meier analysis, the cumulative 6- and 12-month incidences of aneurysm occlusion were $38.2 \%$ and $77.8 \%$, respectively (Fig. 1). The highest observed cumulative incidence of occlusion was $85.1 \%$. The cumulative incidence of aneurysm occlusion was not found to vary according to differences in aneurysm location (Fig. 2A) or maximum aneurysm diameter (Fig. 2B). No instances of aneurysm rupture or rerupture after PED treatment were observed. Similarly, no aneurysms recurred once occlusion had been confirmed via MRA, CTA, or DSA imaging.

\section{Proposal of a Follow-Up Imaging Regimen}

These data would support a shift away from performing cerebral angiography at the 6-month time point to initially obtaining either a 12- or an 18-month imaging study. As the composite Kaplan-Meier curve indicates (Fig. 1), the cumulative incidence of aneurysm occlusion did not vary significantly between the 12- and 24-month time points. The composite Kaplan-Meier curve plateaus at the 24-month time point, suggesting that further follow-up imaging studies past this point may not be needed once an aneurysm has become occluded. In our new imaging follow-up strategy (Fig. 3), we propose performing imaging 12 months and 24 months post-PED treatment, as a small (but significant) proportion of aneurysms that were not occluded within the first year became occluded over the next year (Fig. 1).

Of note, the decision to conduct the initial imaging study at a later time point should be weighed against the risk of aneurysm rupture in the latency period. In the pres-
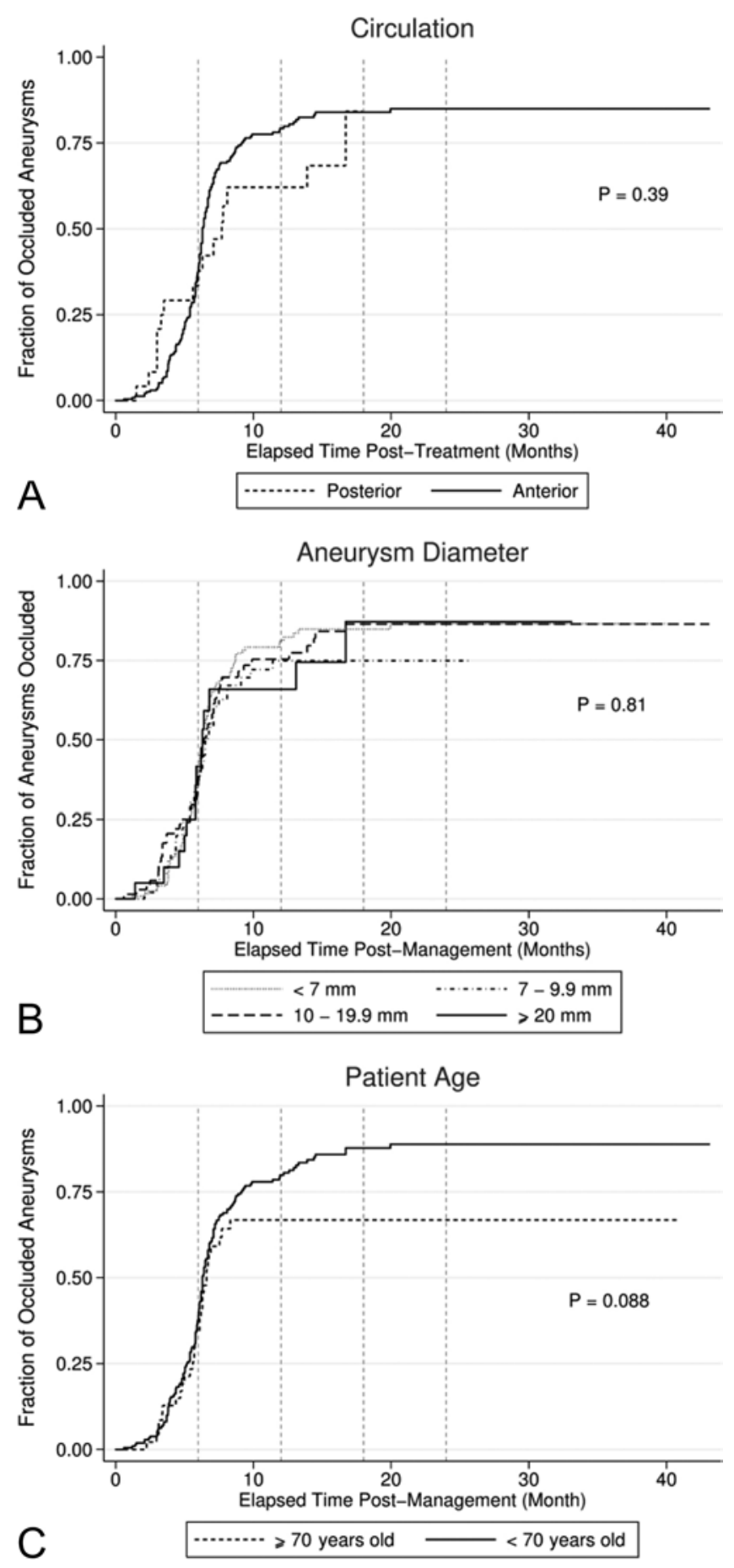

FIG. 2. Kaplan-Meier estimator statistic curves comparing the cumulative incidence of aneurysm occlusion as a function of length of imaging follow-up, for aneurysms in the anterior and posterior intracranial circulations $(\mathbf{A})$, aneurysms with varying maximal diameters (B), and patients $\geq 70$ and $<70$ years old $(\mathbf{C})$.

ent study, none of the aneurysms ruptured after flow diversion, even if the aneurysm were not occluded. Still, there remains concern that an aneurysm that was not occluded carries some rupture risk. Factors such as patient age, hypertension, patient ethnicity, history of subarachnoid 


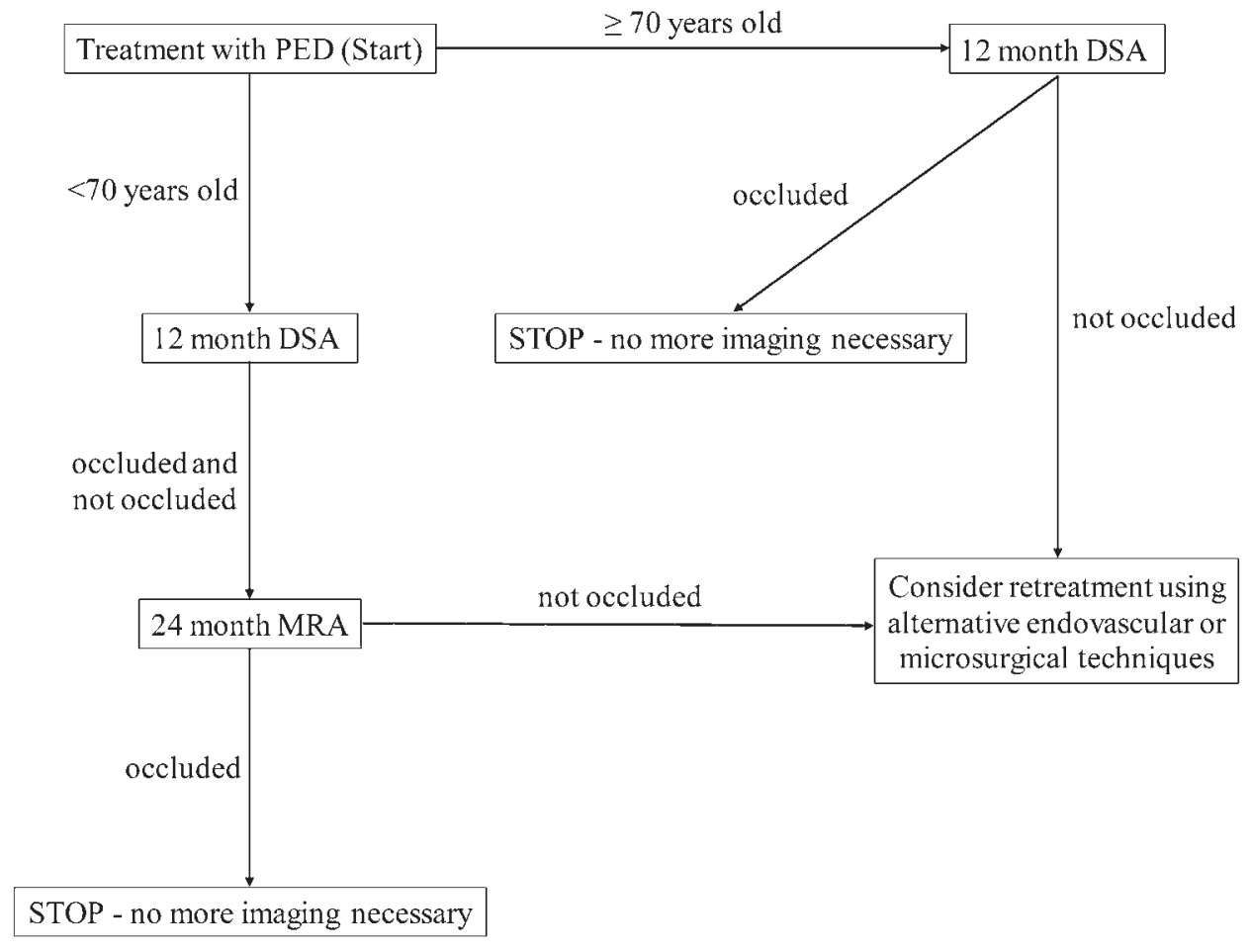

FIG. 3. Proposed follow-up imaging strategy for patients treated with the PED.

hemorrhage, and aneurysm size and location have been previously found to predict the risk of rupture of untreated aneurysms and can be used to guide neurointerventionalists on a case-by-case basis as to whether an earlier initial imaging study is warranted. ${ }^{10}$ Presentation with a symptomatic cranial nerve palsy or with a ruptured aneurysm may represent special circumstances under which an earlier (6-month) DSA study is justifiable as well. The decision to re-treat the aneurysm, similarly, can be made prior to 24 months after the initial PED treatment in high-risk cases to mitigate the risk of rupture and the morbidity and mortality associated with subarachnoid hemorrhage.

The choice of imaging modality used to confirm aneurysm occlusion in a follow-up imaging regimen should be based on an analysis of its diagnostic accuracy and the risks associated with its use. We propose initially performing DSA (at 12 months) followed by MRA (at 24 months). As conventional angiography is the gold standard for assessing aneurysm occlusion status, an angiogram obtained at 12 months posttreatment allows for the rapid and accurate stratification of incompletely occluded aneurysms, which require careful reassessment at subsequent imaging follow-up. Boddu et al. previously reported that contrastenhanced time-resolved MRA is comparable to DSA for the evaluation of aneurysm occlusion after PED placement; they found no significant differences in the quality of visualization or measurable luminal diameter of the reconstructed artery in comparison with conventional angiography. ${ }^{4}$ Given that MRA is noninvasive, is less costly than DSA, and eliminates exposure to ionizing radiation (associated with CT imaging and DSA), it is a safe and cost-effective tool for imaging follow-up. ${ }^{14}$ Once further data comparing the use of DSA with MRA become available and neurointerventionalists' comfort with using MRA for following up aneurysms treated with the PED, increases, MRA may be more frequently used as the imaging modality of choice in the future.

For nearly completely occluded or incompletely occluded aneurysms, the last follow-up imaging study was performed at a median of 12.1 months (IQR 7.0-20.9 months) posttreatment. Of the 11 re-treated aneurysms with subsequent imaging studies, only $27.3 \%$ were occluded at the last imaging follow-up. Whether the remaining cases represent aberrant endothelialization processes remains unclear. The presence of macrophages and monocytes along the length of the portion of the PED covering the aneurysm neck, for example, has been associated with incomplete obliteration and disorganized intraaneurysmal thrombus formation. ${ }^{12}$ Future studies evaluating the role of underlying inflammatory conditions on aneurysm occlusion in patients treated with the PED are needed. As re-treatment with the PED was not associated with high rates of aneurysm occlusion at follow-up, alternative treatment modalities may be considered, including microsurgical clipping. Additional follow-up data would be needed to identify the optimal imaging follow-up strategy for these aneurysms.

A trend toward a decreased cumulative incidence of aneurysm occlusion in older patients ( $\geq 70$ years) was observed in our study $(\mathrm{p}=0.088)$. The Kaplan-Meier curve plateaued prior to the 12-month imaging follow-up (Fig. $2 \mathrm{C}$ ). Modification of the proposed imaging follow-up regimen for patients $\geq 70$ years to include a single 12-month DSA may be warranted. If at this point the aneurysm is found to be occluded, we believe that no further imaging studies are necessary. Conversely, for incompletely oc- 


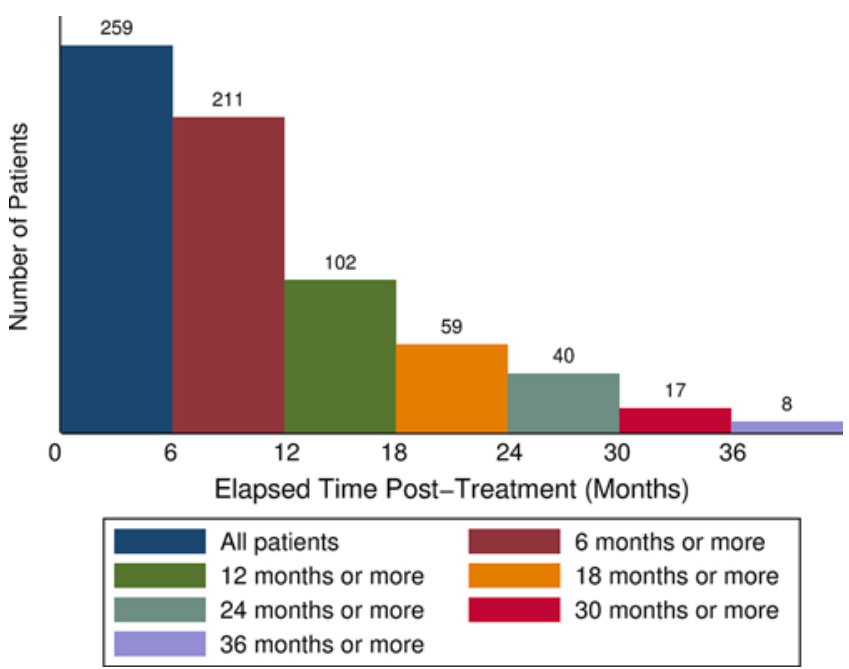

FIG. 4. Histogram depicting the radiographic follow-up duration of aneurysms treated with the PED. Figure is available in color online only.

cluded aneurysms, our data would suggest that occlusion is unlikely to occur after this point in this subset of patients. Re-treatment with the PED or use of an alternative treatment modality may be considered at this time.

\section{Limitations}

This study is limited by its retrospective design. The specificity of the recommendations made with respect to the proposed follow-up imaging strategies may not be generalizable to all cerebrovascular departments, particularly in tertiary and quaternary care centers. Additionally, the threshold for aneurysm re-treatment is at the discretion of the treating neurointerventionalist and cannot be adequately captured in this study. The small number of re-treatments and limited long-term follow-up data for re-treated aneurysms limit extrapolation of their natural history toward the development of a follow-up imaging strategy. In the present study, only $22.8 \%$ of aneurysms had an imaging follow-up study performed at $\geq 18$ months post-PED placement (Fig. 4), necessitating longer-term follow-up imaging data from other studies to assess for hemorrhage and/or aneurysm recurrence following PED treatment.

In patients with multiple PEDs (e.g., for the treatment of both large or giant and wide-necked aneurysms), modification of the follow-up imaging strategies that have been proposed in this study may be necessary on a case-by-case basis. As there are limited data comparing the differences in aneurysm occlusion rates following treatment with single or multiple PEDs, no recommendations were made in the current study with respect to the imaging follow-up strategies that should be utilized in these patients. Matched cohort studies comparing the use of multiple PEDs with a single PED on similarly sized intracranial aneurysms are needed to better elucidate differences in aneurysm occlusion and complication rates and to guide neurointerventionalists as to the optimal follow-up imaging strategies that should be utilized in patients with multiple PEDs.

Finally, as Kallmes et al. recently suggested, rates of recurrence and hemorrhage are similar for both nearly completely occluded and completely occluded aneurysms post-PED treatment. ${ }^{16}$ The authors suggested that trying to achieve complete occlusion may not be associated with improved clinical outcomes, and may actually impose additional risks in these patients. Further data are needed to identify whether a similar follow-up imaging regimen should be used in the management of these 2 types of lesions, and whether additional treatment is necessary.

\section{Conclusions}

Endovascular flow diversion treatment with the PED is routinely performed for the management of intracranial aneurysms. To date, a standardized follow-up imaging strategy has not been proposed for assessing aneurysm occlusion status over time. Using follow-up imaging data on aneurysms treated with the PED at 2 major academic neurovascular centers in the US, we propose a follow-up imaging strategy that incorporates 12-month DSA and 24-month MRA. In elderly patients ( $\geq 70$ years), an alternative follow-up imaging regimen can be used. Further data are needed to develop an imaging follow-up regimen for this subset of patients.

\section{Acknowledgments}

This research was supported by a medical student summer research fellowship grant from the Neurosurgery Research and Education Foundation (NREF).

\section{References}

1. Adeeb N, Griessenauer CJ, Foreman PM, Moore JM, MotieiLangroudi R, Chua MH, et al: Comparison of stent-assisted coil embolization and Pipeline embolization device for endovascular treatment of ophthalmic segment aneurysms: a multicenter cohort study. World Neurosurg 105:206-212, 2017

2. Adeeb N, Griessenauer CJ, Foreman PM, Moore JM, Shallwani $\mathrm{H}$, Motiei-Langroudi R, et al: Use of platelet function testing before pipeline embolization device placement: a multicenter cohort study. Stroke 48:1322-1330, 2017

3. Adeeb N, Griessenauer CJ, Shallwani H, Shakir H, Foreman PM, Moore JM, et al: Pipeline Embolization Device in treatment of 50 unruptured large and giant aneurysms. World Neurosurg 105:232-237, 2017

4. Boddu SR, Tong FC, Dehkharghani S, Dion JE, Saindane AM: Contrast-enhanced time-resolved MRA for follow-up of intracranial aneurysms treated with the Pipeline Embolization Device. AJNR Am J Neuroradiol 35:2112-2118, 2014

5. Bouthillier A, van Loveren HR, Keller JT: Segments of the internal carotid artery: a new classification. Neurosurgery 38:425-433, 1996

6. Brown RD Jr, Broderick JP: Unruptured intracranial aneurysms: epidemiology, natural history, management options, and familial screening. Lancet Neurol 13:393-404, 2014

7. Deutschmann HA, Wehrschuetz M, Augustin M, Niederkorn K, Klein GE: Long-term follow-up after treatment of intracranial aneurysms with the Pipeline embolization device: results from a single center. AJNR Am J Neuroradiol 33:481-486, 2012

8. Fiorella D, Lylyk P, Szikora I, Kelly ME, Albuquerque FC, McDougall CG, et al: Curative cerebrovascular reconstruction with the Pipeline embolization device: the emergence of definitive endovascular therapy for intracranial aneurysms. J Neurointerv Surg 1:56-65, 2009 
9. Fiorella D, Woo HH, Albuquerque FC, Nelson PK: Definitive reconstruction of circumferential, fusiform intracranial aneurysms with the pipeline embolization device. Neurosurgery 62:1115-1120, discussion 1120-1121, 2008

10. Greving JP, Wermer MJ, Brown RD Jr, Morita A, Juvela S, Yonekura M, et al: Development of the PHASES score for prediction of risk of rupture of intracranial aneurysms: a pooled analysis of six prospective cohort studies. Lancet Neurol 13:59-66, 2014

11. Griessenauer CJ, Gupta R, Moore J, Thomas AJ, Ogilvy CS: Ex-vivo release of Pipeline Embolization Device polytetrafluoroethylene (PTFE) sleeves for improved distal landing zone accuracy in-vivo: a technical note. Interv Neuroradiol 22:679-681, 2016

12. Griessenauer CJ, Gupta R, Shi S, Alturki A, Motiei-Langroudi R, Adeeb N, et al: Collar sign in incompletely occluded aneurysms after Pipeline embolization: evaluation with angiography and optical coherence tomography. AJNR Am J Neuroradiol 38:323-326, 2017

13. Griessenauer CJ, Shallwani H, Adeeb N, Gupta R, RangelCastilla L, Siddiqui AH, et al: Conscious sedation versus general anesthesia for the treatment of cerebral aneurysms with flow diversion: a matched cohort study. World Neurosurg 102:1-5, 2017

14. Gupta R, Griessenauer CJ, Adeeb N, Chua MH, Moore JM, Patel AS, et al: Evaluating imaging follow-up strategies and costs of unruptured intracranial aneurysms treated with endovascular techniques: a survey of academic neurovascular centers in the United States. World Neurosurg 94:360-367, 2016

15. Johnston SC, Dowd CF, Higashida RT, Lawton MT, Duckwiler GR, Gress DR: Predictors of rehemorrhage after treatment of ruptured intracranial aneurysms: the Cerebral Aneurysm Rerupture After Treatment (CARAT) study. Stroke 39:120-125, 2008

16. Kallmes DF, Fiorella D, Brinjikji W, Derdeyn CP: Patients, not pictures: why complete occlusion may be a complete disaster. J Neurointerv Surg 9:720-721, 2017

17. Lubicz B, Collignon L, Raphaeli G, De Witte O: Pipeline flow-diverter stent for endovascular treatment of intracranial aneurysms: preliminary experience in 20 patients with 27 aneurysms. World Neurosurg 76:114-119, 2011

18. Lylyk P, Miranda C, Ceratto R, Ferrario A, Scrivano E, Luna HR, et al: Curative endovascular reconstruction of cerebral aneurysms with the Pipeline embolization device: the Buenos Aires experience. Neurosurgery 64:632-643, 2009

19. Nelson PK, Lylyk P, Szikora I, Wetzel SG, Wanke I, Fiorella D: The Pipeline Embolization Device for the intracranial treatment of aneurysms trial. AJNR Am J Neuroradiol 32:34-40, 2011

20. O'Kelly CJ, Spears J, Chow M, Wong J, Boulton M, Weill A, et al: Canadian experience with the Pipeline embolization device for repair of unruptured intracranial aneurysms. AJNR Am J Neuroradiol 34:381-387, 2013

21. Szikora I, Berentei Z, Kulcsar Z, Marosfoi M, Vajda ZS, Lee $\mathrm{W}$, et al: Treatment of intracranial aneurysms by functional reconstruction of the parent artery: the Budapest experience with the Pipeline Embolization Device. AJNR Am J Neuroradiol 31:1139-1147, 2010

22. Tse MM, Yan B, Dowling RJ, Mitchell PJ: Current status of pipeline embolization device in the treatment of intracranial aneurysms: a review. World Neurosurg 80:829-835, 2013

23. Wiebers DO, Whisnant JP, Huston J III, Meissner I, Brown RD Jr, Piepgras DG, et al: Unruptured intracranial aneurysms: natural history, clinical outcome, and risks of surgical and endovascular treatment. Lancet 362:103-110, 2003

24. Willinsky RA, Taylor SM, TerBrugge K, Farb RI, Tomlinson G, Montanera W: Neurologic complications of cerebral angiography: prospective analysis of 2,899 procedures and review of the literature. Radiology 227:522-528, 2003

\section{Disclosures}

Dr. Schirmer: direct stock ownership in NTI. Dr. Thomas: support of non-study-related clinical or research effort from Stryker.

\section{Author Contributions}

Conception and design: Gupta, Moore, Griessenauer. Acquisition of data: Gupta, Moore, Griessenauer, Enriquez-Marulanda, Leadon, Adeeb, Ascanio, Maragkos, Jain, Schmalz. Analysis and interpretation of data: Gupta, Moore, Griessenauer, EnriquezMarulanda, Leadon, Adeeb, Ascanio, Maragkos, Jain, Schmalz. Drafting the article: Gupta, Ogilvy, Moore, Griessenauer, Enriquez-Marulanda, Leadon, Adeeb, Ascanio, Maragkos, Jain, Schmalz. Critically revising the article: Thomas, Ogilvy, Moore, Griessenauer, Alturki, Kicielinski. Reviewed submitted version of manuscript: Thomas, Ogilvy, Alturki, Kicielinski, Schirmer. Statistical analysis: Thomas. Administrative/technical/material support: Thomas, Ogilvy, Alturki, Schirmer. Study supervision: Thomas, Ogilvy, Schmalz, Alturki, Kicielinski, Schirmer.

\section{Correspondence}

Ajith J. Thomas: Beth Israel Deaconess Medical Center, Harvard Medical School, Boston, MA. athomas6@bidmc.harvard.edu. 